\title{
In vitro release of cytotoxic nucleoside analogs from lactide-caprolactone and lactide-glycolide copolymers ${ }^{\star \star}$
}

\author{
Tomasz Kryczka ${ }^{1}$, Maciej Bero ${ }^{2}$, Janusz Kasperczyk ${ }^{2}$, Piotr Dobrzyński², \\ Barbara Marciniec ${ }^{3}$, Maria Popielarz-Brzezińska ${ }^{3}$ and Pawel Grieb ${ }^{1}$ \\ ${ }^{1}$ Medical Research Centre Polish Academy of Sciences, Warsaw, Poland; ${ }^{2}$ Institute of Polymer \\ Chemistry Polish Academy of Sciences, Zabrze, Poland; ${ }^{3}$ Department of Pharmaceutical \\ Chemistry, Karol Marcinkowski University of Medical Sciences, Poznań, Poland
}

Received: 10 September, 2001; revised: 20 December, 2001; accepted: 19 February, 2002

Key words: biodegradable copolymers, cladribine, 5-fluorouracil, sterilization

The aims of our study were to assess the release of cytotoxic nucleoside analogs 5-fluorouracil and 2-chloro-2'-deoxyadenosine from different lactide-glycolide or lactide-caprolactone biodegradable copolymers and the effects of sterilization on this release. The polymers were sterilized either with ethylene oxide at $37^{\circ} \mathrm{C}$, or with gamma radiation ( $15 \mathrm{kGy}, 20 \mathrm{kGy}$, or $25 \mathrm{kGy}$ ). The kinetics of nucleoside release from the copolymers were measured over 50 days. Four copolymers exhibited relatively constant release of nucleosides in micromolar concentrations during the entire observation period. Sterilization with either ethylene oxide or gamma radiation only slightly influenced nucleoside release. Further development of these copolymers as an intracerebral nucleoside delivery system for local treatment of brain tumors is indicated.

Primary malignant brain tumors (gliomas) are currently incurable. Neither surgery nor radiotherapy, alone or combined, change poor prognosis in these diseases. For example, median life expectancy of patients with newly di- agnosed glioblastoma multiforme (the most malignant type of glioma) is less than one year despite treatment [1]. Treatment failure is supposed to be a consequence of the diffuse character of these tumors. Neoplastic glioma

\footnotetext{
${ }^{\star}$ Presented at the 8th International Symposium on Molecular Aspects of Chemotherapy, September, 2001, Gdańsk, Poland.

Supported by the State Committee for Scientific Research (KBN, Poland) grant No. 405F02412.

${ }^{凶}$ Author for correspondence: Tomasz Kryczka, Laboratory of Experimental Pharmacology, Medical Research Centre, Polish Academy of Sciences, A. Pawińskiego 5, 02-106 Warszawa, Poland; phone: (48 22) 608 6474; fax: (48 22) 608 6527; e-mail: tkryczka@mp.pl
}

Abbreviations: 2CdA, 2-chloro-2'-deoxyadenosine (cladribine); 5FU, 5-fluorouracil; aCSF, artificial cerebrospinal fluid; $\mathrm{Me}_{2} \mathrm{SO}$, dimethylsulfoxide. 
cells have the ability to infiltrate brain areas of normal appearance, distant from tumor lesion, so that the entire tumor load can never be surgically removed. Furthermore, some neoplastic cells infiltrating distant brain areas may remain dormant for considerable periods of time and share characteristics of normal glial cells, before they begin to proliferate and give rise to tumor recurrence [2].

Some nucleoside analogs display in vitro cytotoxic or radiosensitizing activity toward many neoplasms, including malignant gliomas, although submicro- or micromolar concentrations are required [3-7]. These compounds seem to be particularily attractive for treatment of malignant gliomas because they preferentially target proliferating cells, and in the central nervous system neither neurons nor normal glial cells display substantial proliferative activity. Unfortunately, when administered peripherally, cytotoxic nucleosides produce systemic toxicity (most frequently bone marrow suppression) at doses far below those required for evoking clinical response.

Intracranial implantation of biodegradable copolymers for local delivery of chemotherapy or for tumor tissue radiosensitization is a promising strategy in the treatment of brain tumors, because it may allow establishing high and sustained concentration of a cytotoxic compound or a radiosensitizer intracerebrally, while peripheral cytotoxicity is avoided [8]. We have developed a series of lactide-caprolactone or lactide-glycolide copolymers loaded with cytotoxic nucleosides 5-fluorouracil (5FU), or cladribine (2-chloro-2'-deoxyadenosine, $2 \mathrm{CdA}$ ). In the present experiments we evaluate the kinetics of release of these nucleosides from the copolymers and compare the results obtained with the use of our experimental system described previously [9] with the in vitro method employed by others $[10,11]$. Our aims were to select copolymers able to release the nucleoside with a sustained micromolar concentration for at least 6 weeks, and to assess the influence of sterilization on the kinetics of nucleoside release.

\section{MATERIALS AND METHODS}

\section{Synthesis of copolymers. Seven} lactide-caprolactone or lactide-glycolide copolymers containing either $2 \mathrm{CdA}$ or $5 \mathrm{FU}$ were synthesized (Table 1). The syntheses of random copolymers of lactide and glycolide $(\# 1-3,7)$ were performed in THF solution at $20^{\circ} \mathrm{C}$, using butyl lithium or lithium t-butoxide as an initiator of the polymerization reaction [12]. The synthesis of the lactide and $\varepsilon$-caprolactone block copolymer (\#4) was conducted as described previously [13]. Random lactide- $\varepsilon$-caprolactone copolymers $(\# 5,6)$ were obtained by bulk polymerization in the presence of zirconium (IV) acetyloacetonate at $100-150^{\circ} \mathrm{C}[14,15]$. The copolymers were precipitated with methanol and dried at $50^{\circ} \mathrm{C}$ under vacuum. Polymer films $0.1-0.3 \mathrm{~mm}$ thick were prepared from copolymer solutions in methylene chloride. The nucleosides were dissolved in dimethyl sulfoxide $\left(\mathrm{Me}_{2} \mathrm{SO}\right)$, added to the polymer solution and stirred. The mixture containing $2 \mathrm{CdA}$ or $5 \mathrm{FU}$ was cast on a glass plate and the solvent was evaporated at ambient temperature. The resultant film was then dried under reduced pressure and stored in a desiccator at room temperature. Copolymer compositions were obtained from ${ }^{1} \mathrm{H}$ - and ${ }^{13} \mathrm{C}-\mathrm{NMR}$ spectroscopic data collected with a Varian Unity Inova spectrometer. The average molecular masses $(m)$ were determined by liquid chromatography and gel permeation chromatography, and the nucleoside analog content by HPLC.

Sterilization of copolymers. All copolymers were sterilized with ethylene oxide. Approximately $10 \times 10 \mathrm{~mm}$ pieces of copolymer films were sterilized with ethylene oxide using a Steri-Vac 4XL 'cool cycle' (temp. $37^{\circ} \mathrm{C}$ for $5.5 \mathrm{~h}$ ). Concurrently three copolymers - approximately $10 \times 10 \mathrm{~mm}$ pieces of each copol- 
ymer film - were sterilized by $\gamma$-irradiation with an RChM-gamma $20{ }^{60}$ Co $\gamma$-ray source, using 15, 20 or $25 \mathrm{kGy}$. Sterilized and nonsterilized samples were tested for the presence of micro-organisms using the methodology recommended by the Polish Pharmaceutical Society [16].

In vitro studies of nucleoside analogs release. The amount of the nucleoside in each of the copolymers was determined by dissolving copolymer film discs (previously weighted), approx. $5 \mathrm{~mm}$ in diameter, in $2 \mathrm{ml}$ of $\mathrm{Me}_{2} \mathrm{SO}$. The content of the nucleoside in the copolymer was then calculated from the result of the chromatographic assay.

To determine the kinetics of nucleoside release, similar copolymer film discs were placed in columns (length $-3 \mathrm{~cm}$, diameter $8 \mathrm{~mm}$ ), immersed in $800 \mathrm{mg}$ of glass beads, kept at $37^{\circ} \mathrm{C}$ and eluted every other day with 1 $\mathrm{ml}$ of artificial cerebrospinal fluid (aCSF), as described previously [9] (experimental system A). Concurrently, to assess the kinetics of nucleoside release with a different method, copolymer films were weighted and placed in separate glass bottles containing $2 \mathrm{ml}$ of aCSF (experimental system B). The bottles were
HPLC assays. Chromatographic assays were performed using a Merck Hitachi LaChrom HPLC System with Autosampler L-7250, Programmable Detector L-7420, Pump L-7100, Integrator D-7500 and $250 \times$ $4.6 \mathrm{~mm} 5 \mu \mathrm{m}$ Supelcosil C18 column. For $2 \mathrm{CdA}$ assay the mobile phase was $0.035 \mu \mathrm{M}$ phosphate buffer containing $3 \%$ acetonitrile (adjusted to $\mathrm{pH} 3.0$ using sodium hydroxide)/ methanol $(84: 16, \mathrm{v} / \mathrm{v})$, the flow rate was $1 \mathrm{ml} / \mathrm{min}$. For $5 \mathrm{FU}$ assay the mobile phase was $0.035 \mu \mathrm{M}$ phosphate buffer containing $3 \%$ acetonitrile (adjusted to $\mathrm{pH} 3.0$ using sodium hydroxide), the flow rate was $0.6 \mathrm{ml} / \mathrm{min}$. UV detection was performed at $264 \mathrm{~nm}$ for $2 \mathrm{CdA}$, $256 \mathrm{~nm}$ for $5 \mathrm{FU}$, and the injection volume was $20 \mu \mathrm{l}$. Quantification of $2 \mathrm{CdA}$ and $5 \mathrm{FU}$ concentration in eluates was performed by the use of external standard calibration curves (prepared from the peak area ratios of freshly prepared standard solutions).

\section{RESULTS}

Table 1 presents the properties of the copolymers. Figure 1 displays the nucleoside ana-

Table 1. Copolymers assessed in the study.

5FU: 5-fluorouracil, 2CdA: 2-chloro-2'-deoxyadenosine, $m$ : average molecular mass, w/w: weight/weight, (*): copolymer sterilized with $\gamma$-radiation, (**): kinetic data not shown.

\begin{tabular}{|c|c|c|c|}
\hline Sample No. & Copolymer content & $\begin{array}{l}\text { Nucleoside content } \\
(\% \mathrm{w} / \mathrm{w})\end{array}$ & $\begin{array}{l}m \\
(\mathrm{kDa})\end{array}$ \\
\hline$\# 1$ & 12\%-glycolide $88 \%$-DL-lactide & $2 \mathrm{CdA}, \quad 1.8$ & 30 \\
\hline$\# 2^{* *}$ & 15\%-glycolide 85\%-DL-lactide & $5 \mathrm{FU}, \quad 11.5$ & 32 \\
\hline$\# 3^{*}$ & 18\%-glycolide $82 \%$-DL-lactide & $2 \mathrm{CdA}, \quad 4.5$ & 30 \\
\hline$\# 4^{* *}$ & $60 \%$-L-lactide $40 \%$ - $\varepsilon$-caprolactone & $2 \mathrm{CdA}, \quad 4.7$ & 32 \\
\hline$\# 5^{* *}$ & poly-L-lactide & $5 \mathrm{FU}, \quad 18.2$ & 30 \\
\hline$\# 6^{*}$ & 70\%-L-lactide $30 \%$-caprolactone & $2 \mathrm{CdA}, \quad 5.5$ & 40 \\
\hline$\# 7^{*}$ & $90 \%[18 \%$-glycolide $82 \%$-L-lactide] + 10\%-L-lactide & 5FU, $\quad 13.3$ & 29.5 \\
\hline
\end{tabular}

sealed and kept at $37^{\circ} \mathrm{C}$ in a water bath. Each day the bottles were opened and the fluid was removed with a pipette and replaced with fresh solution. logs release from the copolymers studied with experimental system A. Figure 2 shows the cumulative release of the nucleosides from these copolymers (Fig. 2A) and the results obtained 


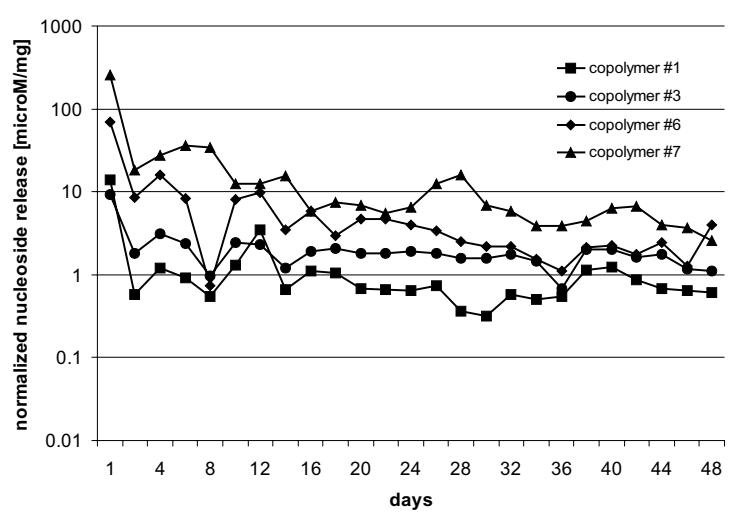

Figure 1. Release of nucleoside analogs from nonsterilized copolymers.

Concentration in eluates, normalized to copolymer weight and plotted vs. time.

with two different experimental systems (Fig. 2B). The effects of different methods of sterilization on nucleoside release are displayed in Fig. 3.

\section{DISCUSSION}

As already mentioned in the introduction, normal brain cells (both glia and neurons) display almost no proliferative activity. Therefore, the increased uptake of nucleosides by proliferating malignant glioma cells should make cytotoxic nucleoside analogs attractive drugs for treatment of these tumors. This is difficult to achieve by systemic delivery, because a drug has to cross the remnants of the blood-brain barrier at the tumor side (known as the blood-tumor barrier). For example, $2 \mathrm{CdA}$ was active toward primary malignant glioma cultures [3-5], but it failed to induce clinical response when administered intravenously [17].

One of the most promising approaches to the treatment of malignant gliomas is the intracerebral delivery of cytotoxic and/or radiosensitizing drugs through implantation of biodegradable polymers. A recent report on the treatment of patients with malignant gliomas by surgical implantation of biodegradable copolymer microspheres containing $5 \mathrm{FU}$ con-

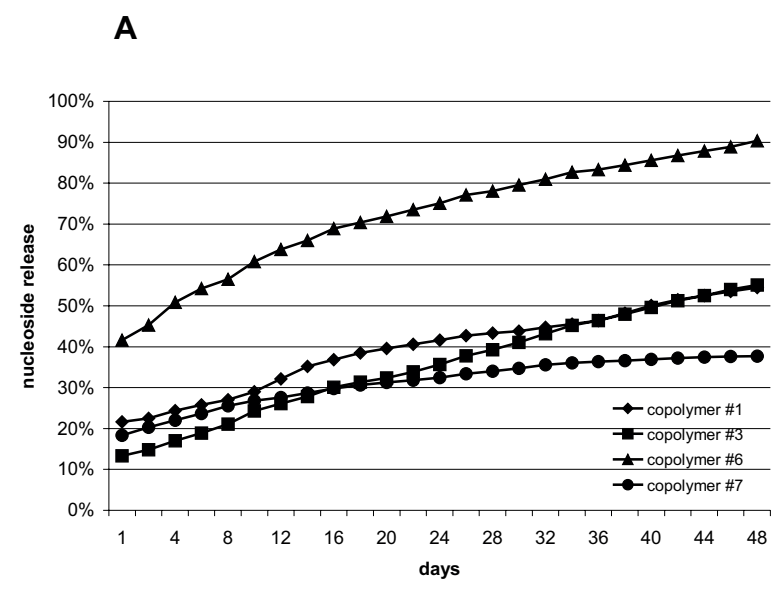

B

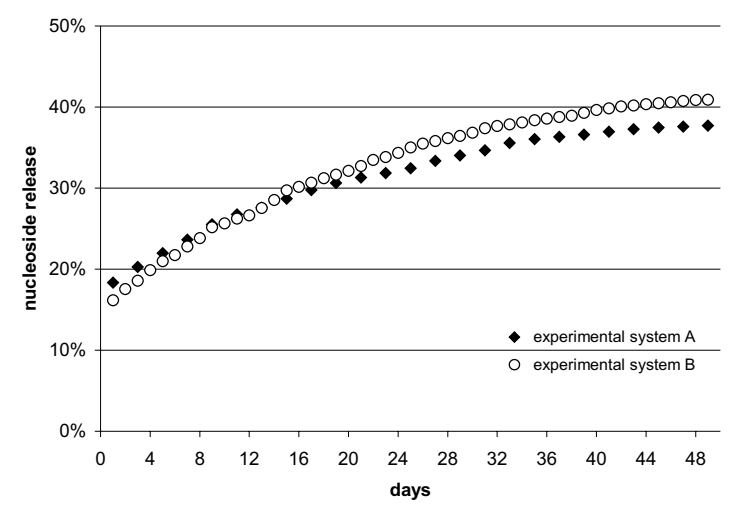

Figure 2. Cumulative release of nucleoside analogs from biodegradable copolymers observed for 50 days.

A, release of nucleoside analogs from copolymers assessed with experimental system A. B, comparison of both experimental systems (copolymer \#7 as an example).

firmed the feasibility of local delivery of nucleoside analogs combined with radiation therapy for the treatment of brain tumors. In that study eight patients with newly diagnosed glioblastoma were treated with polymer microspheres loaded with 5FU implanted in the wall of the surgical bed after resection of tumor, and a modest, albeit significant increase of the median survival time was noted [8].

In malignant gliomas only a fraction of cells (14-44\%) are dividing at any given time [18]. Therefore, to halt tumor recurrence effec- 


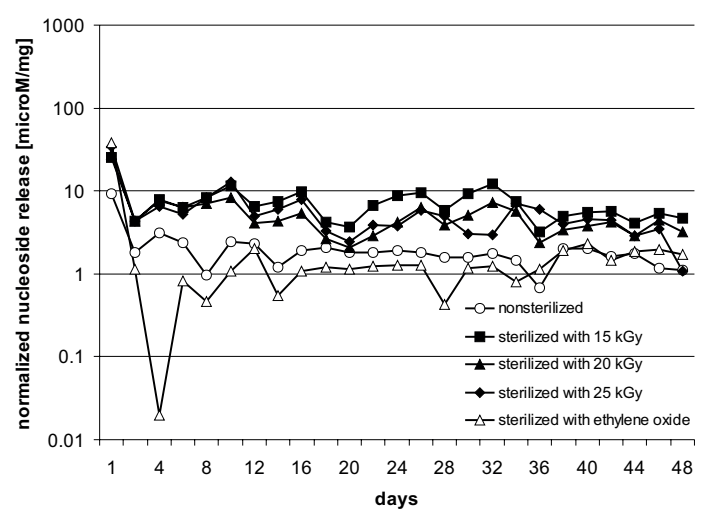

Figure 3. Release of nucleoside analogs from copolymers sterilized with ethylene oxide or $\gamma$-radiation.

Concentration in eluates, normalized to copolymer weight and plotted vs. time). Copolymer \#3 is shown as an example.

tively it may be necessary to deliver a nucleoside to the tumor bed in submicro- or micromolar concentrations for a prolonged time (weeks or even months). Within this time frame a drug not only will fully equilibrate across the more distant areas of the brain, but it may also have a chance to kill more dormant glioma cells as they enter the mitotic cycle.

Biodegradable polymers, described by others, released cytotoxic or radiosensitizing nucleosides for up to three weeks [8, 19]. In our experimental system A four of the copolymers studied were able to release the nucleosides continuously for seven weeks, and micromolar concentrations of $5 \mathrm{FU}$ or $2 \mathrm{CdA}$ in eluates were detected. After seven weeks one of our copolymers (\#6) has released about 90\% of its $2 \mathrm{CdA}$ content, while the other three have released only approximately half of their nucleoside content. Furthermore, our method, assumed to approximate the intracerebral CSF flow, and the method used by others give very similar results (Fig. 2B). It is probable that these copolymers will provide for continuous delivery of a cytotoxic nucleoside for up to 100 days.

We have also evaluated two methods of sterilization of the copolymers. Sterilization with ethylene oxide is simple, but in some previous experiments we observed change of copolymer colour. Apparently ethylene oxide reacts with copolymer surface. Although this reaction appears to have no measurable effect on the kinetics of nucleoside release, in our opinion even minor changes in physical properties of the medical material used for implantation should be avoided. Therefore we favor $\gamma$-radiation as the method of copolymer sterilization.

\section{R E F E R E N C E S}

1. Kornblith, P.L. \& Walker, M. (1988) Chemotherapy for malignant gliomas. J. Neurosurg. 68, 1-17.

2. Laws, E.R. \& Shaffrey, M.E. (1999) The inherent invasiveness of cerebral gliomas: Implications for clinical management. Int. J. Dev. Neurosci. 17, 413-420.

3. Matyja, E., Grieb, P., Ryba, M., Jagielski, J. \& Mossakowski, M.J. (1996) Mitochondrial damage following exposure of organotypic cultures of human malignant gliomas to 2-chloro- and 2-bromo-2'-deoxyadenosine. Folia Neuropathol. 34, 31-39.

4. Grieb, P., Skierski, J., Jagielski, J., Ryba, M. \& Mossakowski, M.J. (1995) DNA protein flow cytometry of dissociated cultures of human anaplastic gliomas. Pattern of proliferation and differentiation, and the effect of a new cytostatic drug cladribine (2-CdA). Folia Neuropathol. 33, 145-152.

5. Ceruti, S., Franceschi, C., Barbieri, D., Malorni, W., Camurri, A., Giammarioli, A.M., Ambrosini, A., Racagni, G., Cattabeni, F. \& Abbracchio, M.P. (2000) Apoptosis induced by 2-chloro-adenosine and 2-chloro-2'-deoxyadenosine in a human astrocytoma cell line: Differential mechanisms and possible clinical relevance. J. Neurosci. Res. 60, 388-400.

6. Yamada, M., Nakagawa, H., Fukushima, M., Shimizu, K., Hayakawa, T. \& Ikenaka, K. 
(1998) In vitro study on intrathecal use of 5-fluoro-2'-deoxyuridine (FdUrd) for meningeal dissemination of malignant brain tumors. J. Neurooncol. 37, 115-121.

7. Bogdahn, U., Weber, H., Zapf, J., Dunisch, G., Lobering, H.G. \& Mertens, H.G. (1987) Therapy of malignant brain tumors: Comparison of the in vitro activities of vidarabin-monophosphate, BCNU and 5-fluorouracil. Acta Neurol. Scand. 75, 28-36.

8. Menei, P., Venier, M.C., Gamelin, E., SaintAndre, J.P., Hayek, G., Jadaud, E., Fournier, D., Mercier, P., Guy, G. \& Benoit, J.P. (1999) Local and sustained delivery of 5-fluorouracil from biodegradable microspheres for the radiosensitization of glioblastoma. Cancer 86, 325-330.

9. Kryczka, T., Grieb, P., Bero, M., Kasperczyk, J. \& Dobrzynski, P. (2000) Kinetics of nucleoside release from lactide-caprolactone and lactide- glycolide polymers in vitro. Acta Biochim. Polon. 47, 59-64.

10. Yuan, X., Fahlman, C., Tabassi, K. \& Williams, J.A. (1999) Synthetic, implantable, biodegradable polymers for controlled release of radiosensitizer. Cancer Biother. Radiopharmaceut. 14, 177-186.

11. Wahlberg, L.U., Almquist, P.M., Glantz, M.J. \& Boethius, J. (1996) Polymeric controlled-release amsacrine chemotherapy in an experimental glioma model. Acta Neurochir. 138, 1323-1330.

12.Bero, M., Dobrzyński, P. \& Kasperczyk, J. (2000) Copolymerization of glycolide with lactide and $\varepsilon$-caprolactone in the presence of initiators containing $\mathrm{Li}, \mathrm{Mg}$ and Ca. Polymers in Medicine and Surgery, PIMS 2000 International Conference Pre-Prints; pp. 390-396, Danube Uniwersity, Published by IOM Communcations Ltd. The Cameleon Press Limited.
13. Bero, M., Adamus, G., Kasperczyk, J. \& Janeczek, H. (1993) Synthesis of block copolymers $\varepsilon$-caprolactone and lactide in the presence of lithium $t$-butoxide. Polymer Bulletin 31, 9-14.

14. Dobrzynski, P., Kasperczyk, J. \& Bero, M. (2000) Synthesis and properties of biodegradable copolymers (PLAGA, PGACap, PLACap) obtained in the presence of new low toxic initiators containing zircon; Polymers in Medicine and Surgery, PIMS 2000 Conference Pre-Prints, pp. 381-389, Danube University, Published by IOM Communcations Ltd. The Cameleon Press Limited.

15. Dobrzynski, P., Kasperczyk, J., Janeczek, H. \& Bero, M. (2001) Synthesis of biodegradable copolymers with the use of low toxic zirconium compounds. Copolymerization of glycolide with L-lactide initiated by $\mathrm{Zr}(\mathrm{acac})_{4}$ Macromolecules 34, 5090-5099.

16. Pharmacopoea Polonica (1996) Edn. V, vol. 2, Polish Pharmaceutical Society, Warsaw.

17. Rajkumar, S.V., Burch, P.A., Nair, S., Dinapoli, R.P., Scheithauer, B., O’Fallon, J., Etzell, P.S., Leitch, J.M., Morton, R.F. \& Marks, R.S. (1999) Phase II north central cancer treatment group study of 2-chlorodeoxyadenosine in patients with recurrent glioma. Am. J. Clin. Oncol. 22, 168-171.

18. Hoshino, T. \& Wilson, C.B. (1979) Cell kinetic analyses of human malignant brain tumors (gliomas). Cancer 44, 956-962.

19. Yuan, X., Dillehay, L.E., Williams, J.R. \& Williams, J.A. (2001) IUdR polymers for combined continuous low-dose rate and high-dose rate sensitization of experimental human malignant gliomas. Int. J. Cancer 96, 118-125. 